Research Article

\title{
Magnitude of social anxiety disorder, and impact on quality of life among medical students, taif city-KSA
}

\begin{abstract}
Background: Social anxiety disorder is a prevalent condition in KSA, especially among people who are in their adolescent years and in the early twenties. It has significant impact on education and employment.

Aim: To estimate the magnitude of Social anxiety disorder (SAD), identify associated factors and assess its effect on the quality of life among the participants.

Subjects and methods: it was a cross sectional study conducted in April and May (2015). It included all medical students in the clinical years at Taif University-KSA. A a validated self-administered questionnaire used as data collection tools.

Results: The study included 283 students out of 338 invited to participate $(R R=83.7 \%)$. Their age mean was 23.5 years and standard deviation of 1 year. Males represented $65 \%$ of them. Based on DSM-V criteria, SAD was diagnosed in $29.3 \%$ of the medical students in the clinical years, Taif University. None of the studied demographic variables was significantly associated with SAD. Students who reported often parental criticism, often parental criticism in front of others and occasional, usual parental provocation or often parental maltreatment, reported higher rate of SAD compared with others, $\mathrm{p}<0.05$. Quality of life based on social adaptation of self-evaluation score ranged between 0 and 60 with a mean of 37.1 and standard deviation of 11.2.
\end{abstract}

Conclusion: The prevalence of SAD constitutes about one third of the medical students in the clinical years, Taif University but it has significant effect on the QoL. Attention with proper education and periodic assessment is highly recommended for university students.

Keywords: magnitude, anxiety disorder, quality of life, medical students
Volume 7 Issue 5 - 2017

\author{
Hadeel N Bin Jarallah,' Fahad K Al Omari, ${ }^{2}$ \\ Imtenan F Altowairiqi, ${ }^{3}$ Khulod K Al Saadi ${ }^{3}$ \\ 'Family medicine specialist, Saudi Arabia \\ ${ }^{2}$ Consultant of Family Medicine, PSH director, Saudi Arabia \\ ${ }^{3}$ Medical collage - Taif University, Saudi Arabia
}

Correspondence: Fahad K Al-Omari, SBFM, ABFM, Consultant of Family Medicine, PSH director, Saudi Arabia,

Email dromari2010@gmail.com

Received: March II, 2017 | Published: April 24, 2017

\section{Introduction}

Social anxiety disorder (SAD) is a common disorder, persistent, disabling condition, in which the central psychopathological feature is an intense fear of scrutiny and negative evaluation by others, with a consequent avoidance of social encounters and markedly restricted social functioning. ${ }^{1}$ There is an evidence of genetic transmission of $10 \%$, and environmental effects such as lack of warmth, overprotection and the behaviors of the parents that promote child anxiety which are likely to be significant. ${ }^{2}$

Patients with SAD also inevitably suffer from the reduced quality of life because of their condition. ${ }^{3,4}$ More so, SAD can lead to other problems such as, but not limited to, alcohol and substance abuse, depression, and other problems which are linked to anxiety. ${ }^{5}$

$\mathrm{SAD}$ is a prevalent condition in KSA, constituting approximately $13 \%$ of all neurotic disorder seen in psychiatric clinic, ${ }^{6}$ especially among people who are in their adolescent years and in the early twenties.

Elsewhere in the western world, SAD among adolescents and young adults has a lifetime incidence of $7-13 \% .^{5}$ It has significant impact on education and employment, (lower levels of educational achievement and lower incomes). ${ }^{6}$ The rationale of this research started when the researchers met several cases that suffer from SAD during their training especially among newly graduated medical staff and how it affect their quality of life.

The aims of the research are to know the prevalence of SAD among medical college students in clinical years and associated risk factors with studying the impact on quality of life in order to set recommendations to improve the quality of life and performance of future physicians.

There are many studies which were made in different parts of Saudi Arabia as well as other countries. SAD is a notably common disorders among Saudis, constituting about $13 \%$ of all neurotic disorders seen in clinics. ${ }^{4}$

However, In 2005, Bassiony studied the prevalence of depression the patients with SAD and the relationship between the severity of SAD symptoms and depression in Saudi Arabia. The author noted in patients with severe SAD were four times more likely to have depression than the patients with mild or moderate SAD even after controlling for confounding sociodemographic and clinical factors. The Early recognition and treatment of SAD, especially the severe subtype, may prevent the occurrence of depression. ${ }^{7}$

Moreover, Al-Gelban studied the prevalence rates and severity of depression, anxiety and stress among Saudi adolescent boys in 2007, on secondary school boys at Abha, KSA. The author noted, $48.9 \%$ of the subjects had anxiety and $35.5 \%$ had stress, depression, anxiety and stress were strong, positively, and significantly correlated. ${ }^{8}$

The author also studied the mental health of Saudi adolescent secondary school girls in the same city in 2009 . He noted, most prevalent mental symptoms in the 545 female students were phobic anxiety $16.4 \%{ }^{9}$

In the 2009, and in the same city, Mahfouz and his colleagues discussed mental health on the secondary school boys and girls, too. 
Also they found that there were different demographic variables which can have a significant effect on the mental health of adolescents such as father education, type of educational institution, and ranking among siblings, among other factors. ${ }^{10}$

Moreover, the study of El-Tantawy, Raya, Al-Yahya, and Zaki in 2010, at the Burydah mental hospital was directed toward an examination of the reduction of the quality of life on patients suffering from SAD. They found that the prevalence of SAD among the outpatient clinic attendance was $5.63 \%$ and the quality of life among these people was relatively lower compared to the controlled group which has been used in their inquiry. ${ }^{11}$

There were other studies in other countries including, a study done by Kadri and his colleges in 2007, to assess the prevalence and co morbidity of anxiety disorders in Moroccan subjects. Among 800 subjects, $25.5 \%$ met criteria of at least one anxiety disorder; SAD constitutes about $3.4 \% .^{12}$

Moreover, In 2003, Chartier and his colleagues studied the co morbidity of SAD at a mental health hospital in Canada and they found fifty-two percent of respondents with lifetime SAD reported at least one other lifetime mental disorder and $27 \%$ reported three or more lifetime mental disorders. SAD, in this sample, was strongly co morbid with anxiety and affective disorders, and moderately co morbid with substance abuse. ${ }^{13}$

\section{Subjects and methods}

Using Cross-sectional design, it was conducted at Taif University in Taif city which is located in the western region of Saudi Arabia. The college of medicine at the Taif University is one of the most recent medical institutions in Saudi Arabia. This study was conducted in April and May (2015). It includes all clinical years medical students at Taif University constituted the target population of this study. The inclusion criteria include all clinical year medical students $\left(5^{\text {th }}\right.$ and $6^{\text {th }}$ levels) regularly attending the Medical College (2014-2015), both male and female of all nationalities while the exclusion criteria include those who refused to participate, be absent and participants not complete their questionnaire.

A self-administered questionnaire consists of demographic data for the participants, structured clinical interview for DSM-V for social anxiety disorder, disease- related risk factors and social adaptation self-valuation scale (SASS).

In order to diagnose social SAD among the chosen respondents, the researcher has used a self-administered questionnaire including the structured clinical interview for DSM-V for social anxiety disorder.

The impact of the SAD on the quality of the life will be assessed by Social adaptation self-evaluation scale (SASS) which includes 21 items that explore the areas of work and leisure, family and extra-family relationships, intellectual interests, satisfaction in roles and participant perception of his ability to manage and control his environment. ${ }^{14}$ The validated self-administered questionnaires were distributed to the students by the researcher and by trained researcher assistant manually and they explained to the participant how to they fill the questionnaire.

The collected data were verified and coded prior to computerized data entry. The Statistical Package for Social Sciences (SPSS version 20.0) was used for data entry and analysis. Percentages, mean, range and SD were used as descriptive statistics. Chi-square test was used for testing the association and/or difference between categorical variable.
A p-value of 0.05 or less was adopted for statistical significance. The reliability and credibility of the findings from the proposed research, certain ethical standards were also being taken into account and data were treated confidentially during all stages of the research.

\section{Results}

Two hundred and eighty three (283) students were included in the study out of 338 invited to participate (response rate $=83.7 \%$ ). Their age ranged between 21 and 27 years with a mean of 23.5 years and standard deviation of 1year with $61.1 \%$ of them were under 24 years old. Males represent $65 \%$ of them. Almost two-thirds of them (63.3\%) were recruited from fifth academic level. Majority of them (99.6\%) were Saudis and singles $(88.7 \%)$. Among majority of the students $(85.7 \%)$ parents were living together while they were divorced or separated among $7.4 \%$ of them.

\section{Diagnosis of social anxiety disorder}

From Table 1, DSM-V questionnaire revealed that: One hundred and twenty four students $(43.8 \%)$ had marked fear or anxiety of one or more social situations in which the individual is exposed to possible scrutiny by others. Based on these criteria, social anxiety disorder was diagnosed in eighty three students representing $29.3 \%$ of the clinical year's medical students, Taif University as displayed from Figure 1.

Risk factors for social anxiety disorder: Parental anger at students was often or usually among $19.4 \%$ of them whereas parental criticism was often or usually among $14.8 \%$ of them. Criticism by parents in front of others was reported as often or usually by $14.5 \%$ of the students. Almost one third of the students (35.4\%) reported parental protection in an exaggerated manner most of the time. Frequent familial provocation was reported by $23.7 \%$ of the students whereas parental maltreatment was described as often or usually by $13.4 \%$ of them.

Regarding type of parental maltreatment, the most frequent type was emotional $(14.8 \%)$, followed by neglect $(6.7 \%)$ and physical $(3.2 \%)$. All types were reported by $11 \%$ of the students. Family history of social anxiety disorder was reported by 34 students representing $12 \%$ of them.

\section{Factors associated with social anxiety disorder}

Personal data: As shown in Table 2, none of personal data (age, gender, birth order, academic level, marital status, parental education and parental living status) was significantly associated with social anxiety disorder among clinical year's medical students, Taif University.

Risk factors: As illustrated in Table 3, students who reported often parental criticism reported the highest rate of SAD (43.3\%) whereas those who reported never parental criticism showed the lowest rate of SAD (19.8\%). The association between parental criticism and SAD was statistically significant, $\mathrm{p}=0.023$.

Quality of life: Quality of life based on social adaptation of selfevaluation score ranged between 0 and 60 with a mean of 40.2 and standard deviation of 6.8 as illustrated in Figure 2.

\section{Factors associated with SASS score}

Personal factors: As illustrated from table 4, the SASS score was significantly associated with student's academic level, father and mother education. 
Table I Structured clinical interview for DSM-V for social anxiety disorder among the medical students in the clinical years, Taif University

\begin{tabular}{|c|c|c|}
\hline & YES N (\%) & NO N (\%) \\
\hline \multicolumn{3}{|c|}{$\begin{array}{l}\text { Do you have marked fear or anxiety of one or more social situations in which the individual is exposed } \\
\text { to possible scrutiny by others? Examples include social interactions (e.g., having a conversation, meeting } 124 \text { (43.8) } \\
\text { unfamiliar people), being observed (e.g., eating or drinking), and performing in front of others (e.g., } \\
\text { giving a speech). }\end{array}$} \\
\hline $\begin{array}{l}\text { Does the fear that you feel is accompanied with anxiety, feeling of humiliating, embarrassing or feeling } \\
\text { of being rejected from others? }\end{array}$ & $110(38.9)$ & $173(6 \mid .1)$ \\
\hline Does the social situation almost always provoke your fear or anxiety? & $91(32.2)$ & $192(67.8)$ \\
\hline Are the social situations avoided or endured with intense fear or anxiety? & $90(31.8)$ & $193(68.2)$ \\
\hline Is your fear or anxiety out of proportion? & $79(27.9)$ & $204(72.1)$ \\
\hline Have you been suffering from this fear, anxiety, or avoidance for six months or more? & $83(29.3)$ & $200(70.7)$ \\
\hline
\end{tabular}

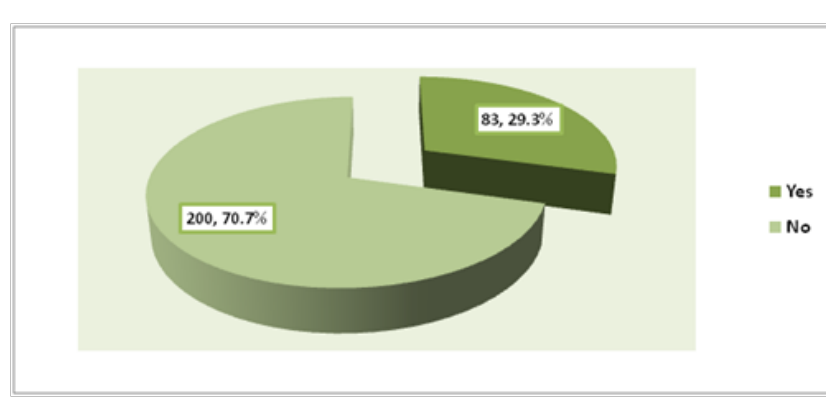

Figure I Prevalence of social anxiety disorder among the clinical years medical students, Taif University.

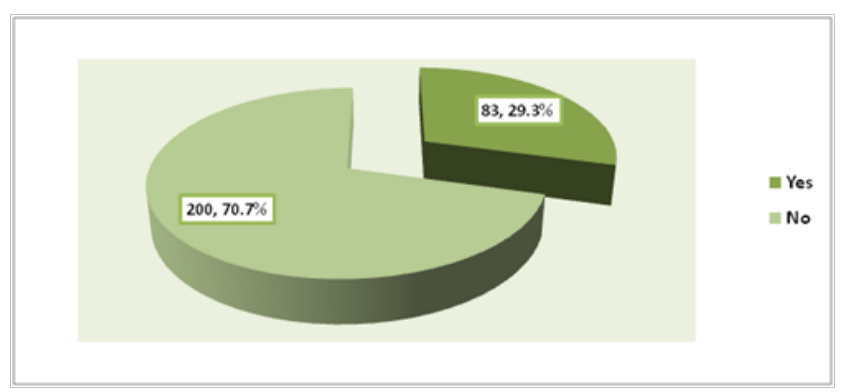

Figure 2 Distribution of social adaptation self-evaluation score (SASS) among clinical years' medical students, Taif University.

\section{Risk factors for SAD}

SASS score was significantly the lowest among students whose parents often criticize them $(37.60 \pm 6.17)$, whose parents often criticize them in front of others $(37.27 \pm 6.17)$, whose parents usually provoked them (38.68 \pm 8.47$)$, and students whose parents usually maltreated them $(36.29 \pm 5.36)$. Parental anger, parental exaggerated protection, type of parental maltreatment and family history of SAD were not significantly associated with SASS score.

It is evident that the score of SASS was higher among students with no SAD (41.20 \pm 6.73$)$ than those with SAD (38.82 \pm 10.42$)$. The difference was statistically significant, $\mathrm{p}=0.02$.

\section{Discussion}

Within the Saudi context, some important studies have been conducted on SAD in young people, although less is known about the prevalence of SAD in these populations. It is the most frequent mental-health-related problem among Saudi adolescents, with a rate of around $17.3 \%{ }^{10}$ Another study, of 545 Saudi female students, found a prevalence rate of $16.4 \%$ for phobic anxiety. ${ }^{9}$
In another Saudi study, it was reported as a prevalent condition constituting approximately $13 \%$ of all neurotic disorder seen in psychiatric clinic, ${ }^{4}$ especially among young people; hence, we have included female medical university students in their clinical years as target participants in the current study. A prevalence of $29.3 \%$ based on DSM-V has been reported among them in the present study. However, in spite of the prevalence of this $\mathrm{SAD}$, it has also been recognized that such social condition is an area which is often under-studied and poorly recognized, often not diagnosed, in the case of people who are suffering from such disorder. ${ }^{15}$

In USA, it has been estimated that the lifetime prevalence of this disorder is at $12 \%$ and about half of these cases of SAD are concerned about avoidance or fear to be in various social situations. Although there were different treatments which were made available to people who were suffering from this condition, it was assumed that such treatments were under-recognized. ${ }^{16}$ In Germany (Munich), Beesdo, et al., ${ }^{17}$ conducted a study to estimate the cumulative incidence of SAD among adolescents and young adults (14-24 years). The overall cumulative incidence for SAD was $11.0 \%$ for the total sample. ${ }^{17}$ There is a strong support to the notion that early identification and intervention with socially anxious adolescents might therefore reduce risk for depressive disorders in adolescence and young adulthood, even more so because of previous demonstrations that SAD-comorbid depression is strongly associated with a more malignant course of depressive illness in terms of more suicidal ideation and suicide attempts, more depressive symptoms during episodes, more frequent and/or more protracted depressive episodes, ${ }^{18}$ and poorer depression outcomes. ${ }^{19}$ However, prevention of depression is obstructed by the fact that few individuals with SAD receive adequate treatment, despite overall increased health care utilization. ${ }^{20,21}$

Sibling position might have an impact on SAD because some studies have reported increased rates of social anxiety among firstborn children ${ }^{22}$ and some reported it among children born later. ${ }^{23}$ However, other investigators have reported that first born children show less trait anxiety than later-born siblings and that increasing adult fearfulness correlates with increasing birth order in the sib ship. ${ }^{23}$ Thus, to date, reports on birth-order are inconclusive. In the present study, rate of SAD was not significantly associated with birth disorder. Parents are hypothesized to affect the potentiality of SAD in their young by either (a) a genetic predisposition or (b) familial environments that are rejecting, emotionally distant, or overprotective and possessive. ${ }^{24,25}$ In agreement with that, the current study demonstrated significant association between SAD among female medical students from one side and parental criticism especially in front of others, parental provocation and maltreatment from the other side. In addition, family history of SAD was proved as a risk factor in the present study. In accordance with what has been reported by many studies, this study 
confirmed that the quality of life among students with SAD is lower compared to those without $\mathrm{SAD}$, which is statically significant. In Saudi Arabia, El-Tantawy, et al., ${ }^{26}$ confirmed that Saudi adolescents with SAD scored less on the World Health Organization's Quality of Life Questionnaire (QoL) (WHOQOL-BREF) scale than Saudi adolescents without SAD. ${ }^{26}$

Table 2 Association between personal data of the participants and social anxiety disorder

\begin{tabular}{|c|c|c|c|}
\hline & \multicolumn{2}{|c|}{ Social Anxiety Disorder } & \multirow[t]{2}{*}{ p-value* } \\
\hline & $\begin{array}{l}\text { No } \\
N=200 \quad N(\%)\end{array}$ & $\begin{array}{l}\text { Yes } \\
N=83 \quad N(\%)\end{array}$ & \\
\hline \multicolumn{4}{|l|}{ Gender } \\
\hline Females $(n=99)$ & $75(75.8)$ & $24(24.2)$ & 0.168 \\
\hline Males $(n=184)$ & $125(67.9)$ & $59(32.1)$ & \\
\hline \multicolumn{4}{|l|}{ Age in Years } \\
\hline$<24(n=173)$ & $127(73.4)$ & $46(26.6)$ & 0.204 \\
\hline$\geq 24(n=110)$ & $73(66.4)$ & $37(33.6)$ & \\
\hline \multicolumn{4}{|l|}{ Academic Level } \\
\hline 5 th $(n=179)$ & $122(68.2)$ & $57(3 \mid .8)$ & 0.223 \\
\hline 6 th $(n=104)$ & $78(75.0)$ & $26(25.0)$ & \\
\hline \multicolumn{4}{|l|}{ Marital Status } \\
\hline Married $(n=32)$ & $22(68.8)$ & $10(3 \mid .2)$ & 0.8 \\
\hline Single $(n=251)$ & I 78 (70.9) & $73(29.1)$ & \\
\hline \multicolumn{4}{|l|}{ Birth Order } \\
\hline Ist $(n=84)$ & $61(72.6)$ & $23(27.4)$ & $0.77 \mathrm{I}$ \\
\hline 2nd $(n=4 I)$ & 31 (75.6) & $10(24.4)$ & \\
\hline $3 r d(n=42)$ & $28(66.7)$ & $14(33.3)$ & \\
\hline$>3 r d(n=116)$ & $80(69.0)$ & $36(31.0)$ & \\
\hline \multicolumn{4}{|l|}{ Father's Education } \\
\hline Illiterate $(n=\mid 4)$ & $9(64.3)$ & $5(35.7)$ & 0.655 \\
\hline Primary $(n=27)$ & $19(70.4)$ & $8(29.6)$ & \\
\hline Intermediate $(n=37)$ & $22(59.5)$ & $15(40.5)$ & \\
\hline Secondary $(n=55)$ & $40(72.7)$ & $15(27.3)$ & \\
\hline University $(n=86)$ & $62(72.1)$ & $24(27.9)$ & \\
\hline Postgraduate $(n=64)$ & $48(75.0)$ & $1625.0)$ & \\
\hline \multicolumn{4}{|l|}{ Mother's education } \\
\hline Illiterate $(n=37)$ & $28(75.7)$ & $9(24.3)$ & 0.452 \\
\hline Primary $(n=6 I)$ & $39(63.9)$ & $22(36.1)$ & \\
\hline Intermediate $(n=25)$ & $18(72.0)$ & $7(28.0)$ & \\
\hline Secondary $(n=48)$ & $37(77.1)$ & II (22.9) & \\
\hline University $(n=73)$ & $54(74.0)$ & $19(26.0)$ & \\
\hline Postgraduate $(n=39)$ & $24(6 \mid .5)$ & $15(38.5)$ & \\
\hline \multicolumn{4}{|l|}{ Parental Living Status } \\
\hline \multirow{3}{*}{$\begin{array}{l}\text { Living Together }(n=243) \\
\text { Divorced/Separated } \\
(n=21) \\
\text { Widowed }(n=19)\end{array}$} & I $70(70.0)$ & $73(30.0)$ & 0.238 \\
\hline & I 8 (85.7) & $3(14.3)$ & \\
\hline & $12(63.2)$ & $7(36.8)$ & \\
\hline
\end{tabular}

*Chi-square test

Table 3 Association between risk factors of the participants and SAD

\begin{tabular}{llll}
\hline & \multicolumn{2}{l}{ Social Anxiety Disorder } & p-value* \\
\hline & No $\mathbf{N}=\mathbf{2 0 0}$ & Yes N=83 & \\
& $\mathbf{N}(\%)$ & $\mathbf{N}(\%)$ & \\
\hline Paternal Anger & & & \\
Never (98) & $73(74.5)$ & $25(25.5)$ & 0.132 \\
Occasionally (I30) & $92(70.8)$ & $38(29.2)$ & \\
Often (42) & $24(57.1)$ & I8 (42.9) & \\
Usually (13) & II (84.6) & $2(15.4)$ & \\
Paternal Criticism & & & \\
Never (I I6) & $93(80.2)$ & $23(19.8)$ & 0.023 \\
\hline
\end{tabular}

Table Continued...

\begin{tabular}{|c|c|c|c|}
\hline & \multicolumn{2}{|c|}{ Social Anxiety Disorder } & \multirow[t]{2}{*}{ p-value* } \\
\hline & $\begin{array}{l}\text { No } N=200 \\
N(\%)\end{array}$ & $\begin{array}{l}\text { Yes } N=83 \\
N(\%)\end{array}$ & \\
\hline Occasionally (125) & $82(65.6)$ & $43(34.4)$ & \\
\hline Often (30) & $17(56.7)$ & $13(43.3)$ & \\
\hline Usually (12) & $8(66.7)$ & $4(33.3)$ & \\
\hline \multicolumn{4}{|c|}{ Paternal Criticism in front of Others } \\
\hline Never (165) & I33 (80.6) & $32(19.4)$ & $<0.001$ \\
\hline Occasionally (77) & $49(63.6)$ & $28(36.4)$ & \\
\hline Often (30) & $12(40.0)$ & $18(60.0)$ & \\
\hline Usually (I I) & $6(54.5)$ & $5(45.5)$ & \\
\hline \multicolumn{4}{|c|}{ Paternal Exaggerated Protection } \\
\hline Never (94) & $74(78.7)$ & $20(2 I .3)$ & 0.086 \\
\hline Occasionally (89) & $60(67.4)$ & $29(32.6)$ & \\
\hline Often (6I) & $37(60.7)$ & $24(39.3)$ & \\
\hline Usually (39) & $29(74.4)$ & $10(25.6)$ & \\
\hline \multicolumn{4}{|l|}{ Paternal Provoking } \\
\hline Never (I I7) & $92(78.6)$ & $25(2 \mathrm{I} .4)$ & 0.029 \\
\hline Occasionally (99) & $69(69.7)$ & $30(30.3)$ & \\
\hline Often (4I) & $25(61.0)$ & $16(39.0)$ & \\
\hline Usually (26) & $14(53.8)$ & $12(46.2)$ & \\
\hline \multicolumn{4}{|c|}{ Paternal Maltreatment } \\
\hline Never (182) & I 44 (79.1) & 38 (20.9) & $<0.001$ \\
\hline Occasionally (63) & $38(60.3)$ & $25(39.7)$ & \\
\hline Often (24) & $10(4 \mid .7)$ & I4 (58.3) & \\
\hline Usually (I4) & $8(57.1)$ & $6(42.9)$ & \\
\hline \multicolumn{4}{|c|}{ Type of Parental Maltreatment } \\
\hline Physical (9) & I (II.I) & $8(88.9)$ & $<0.001$ \\
\hline Emotional (42) & $28(66.7)$ & I4 (33.3) & \\
\hline Neglect $(n=19)$ & 14 (73.7) & $5(26.3)$ & \\
\hline All (3I) & $13(4 \mid .9)$ & $18(58.1)$ & \\
\hline \multicolumn{4}{|c|}{ Family History of SAD } \\
\hline Yes (34) & $19(55.9)$ & $15(44.1)$ & 0.043 \\
\hline No (249) & $|8|(72.7)$ & $68(27.3)$ & \\
\hline
\end{tabular}

*Chi-square test

Table 4 Distribution of social adaptation self-evaluation score according to personal characteristics of among the medical students in the clinical years, Taif University

\begin{tabular}{llll}
\hline & \multicolumn{2}{l}{$\begin{array}{l}\text { Social Adaptation Self- } \\
\text { Evaluation Scale }\end{array}$} & P-Value \\
\hline & Mean & SD & \\
\hline Gender & & & \\
Females $(n=99)$ & 40.33 & 6.87 & $0.797^{*}$ \\
Males $(n=184)$ & 40.59 & 8.64 & \\
Age in Years & & & \\
$<24(n=173)$ & 40.11 & 7.9 & $0.306^{*}$ \\
$\geq 24(n=110)$ & 41.12 & 8.3 & \\
Academic Level & & & \\
5th $(n=179)$ & $39.5 I$ & 8.24 & $0.006^{*}$ \\
6th $(n=104)$ & 42.21 & 7.46 & \\
Marital Status & & & \\
Married (n=32) & 41.28 & 6.29 & $0.562^{*}$ \\
Single (n=25I) & 40.4 & 8.26 & \\
Birth Order & & & \\
Ist $(n=84)$ & 39.96 & 8.15 & $0.216^{* *}$ \\
2nd $(n=4 I)$ & 42.34 & 6.56 & \\
3rd $(n=42)$ & 41.76 & 7.93 & \\
$>3 r d(n=116)$ & 39.78 & 8.45 & \\
Father's Education & & &
\end{tabular}


Table Continued...

\begin{tabular}{llll}
\hline & \multicolumn{2}{l}{$\begin{array}{l}\text { Social Adaptation Self- } \\
\text { Evaluation Scale }\end{array}$} & P-Value \\
\hline & Mean & SD & \\
\hline Illiterate $(n=14)$ & 35.71 & 6.01 & $0.005^{* *}$ \\
Primary $(n=27)$ & 38.59 & 7.59 & \\
Intermediate $(n=37)$ & 37.51 & 6.72 & \\
Secondary $(n=55)$ & 41.02 & 7.41 & \\
University $(n=86)$ & 41.47 & 9.24 & \\
Postgraduate $(n=64)$ & 42.34 & 7.37 & \\
Mother's Education & & & \\
Illiterate $(n=37)$ & 38.14 & 7.19 & $0.017^{* *}$ \\
Primary $(n=6 I)$ & 38.85 & 7.1 & \\
Intermediate $(n=25)$ & 40.72 & 6.72 & \\
Secondary $(n=48)$ & 40.02 & 7.42 & \\
University $(n=73)$ & 43.11 & 9.11 & \\
Postgraduate $(n=39)$ & 40.9 & 8.72 & \\
Parental Living Status & & & \\
Living together $(n=243)$ & 40.49 & 7.97 & $0.887^{* *}$ \\
Divorced/separated $(n=21)$ & 41.14 & 8.12 & \\
Widowed $(n=19)$ & 39.89 & 9.48 & \\
\hline
\end{tabular}

* Student's t-test **ANOVA test

Also, the findings by Hambrick have shown that social anxiety disorder has an adverse effect on life satisfaction. SAD affects the quality of life of a person severely and thus makes him or her unstable both physically and psychologically. ${ }^{27}$ Alkhathami \& Wittchen's ${ }^{28,29}$ findings approved association between SAD and quality of life, physical and role functioning.

The study of Lochner and colleagues revealed that SAD affects quality of life, especially in matters which are related to leisure activities and social life. ${ }^{30}$ Furthermore, the study of Barrera and Norton (2009) has also found that the quality of life of patients with $\mathrm{SAD}$ is poorer, same with those who are suffering from general anxiety disorder and panic disorder. ${ }^{31}$

\section{Conclusion}

The prevalence of SAD is high among the participants It constitutes around one third of the targeted medical students. In addition, important significant risk factors for SAD have been identified including parental criticism (particularly in front of others), parental provocation, parental maltreatment and family history of SAD. The association between SAD and the students' quality of life was proved to be significant, although QOL score was higher among students with no SAD. Early recognition of SAD and early initiation of treatment are required with proper health education are highly recommended to reduce the adverse burden among students with SAD.

\section{Acknowledgments}

None.

\section{Conflicts of interest}

Author declares there are no conflicts of interest.

\section{Funding}

None.

\section{References}

1. Murray L, Cooper P, Creswell C, et al. The effects of maternal social phobia on mother-infant interactions and infant social responsiveness. $J$ Child Psychol Psychiatry. 2007;48(1):45-52.
2. Nelson EC, Grant JD, Bucholz KK, et al. Social phobia in a populationbased female adolescent twin sample: Comorbidity and associated suicide related symptoms. Psychol Med. 2000;30(4):797-804.

3. Von dawans B. Neuropeptidergic modulation of social behavior in health and social phobia. Verlag, Germany. 2008.

4. Chaleby K. Social phobia in Saudis. Soc Psychiatry Psychiatr Epidemiol. 1987;22:167-170.

5. Furmark T. Social phobia: overview of community surveys. Acto Psychiatr Scand. 2002;105(2):84-93.

6. Patel A, Knapp M, Henderson J, et al. The economic consequences of social phobia. J Affect Disord. 2002;68(2-3):221-233.

7. Bassiony MM. Social anxiety disorder and depression in Saudi Arabia. Depress Anxiety. 2005;21(2):90-94.

8. Al-Gelban K. Depression, anxiety, and stress among Saudi adolescent school boys. J R Soc Promot Health. 2007;127(1):33-37.

9. Al-Gelban K. Prevalence of psychological symptoms in Saudi secondary school girls in Abha, Saudi Arabia. Annuals of Saudi Medicine. 2009;21(4):275-279.

10. Mahfouz AA, Abdelmoneim I, Al-Gelban KS, et al. Adolescents' Mental Health in Abha City, Southwestern Saudi Arabia. Int J Psychiatry Med. 2009;39(2):169-177.

11. El-Tantawy AM, Raya YM, Al-Yahya AH, et al. Social phobia among patients attending the outpatient clinics of Buraydah Mental Health Hospital, Al-Gassim, KSA. Current Psychiatry. 2010;17(2):35-43.

12. Kadri N, Agoub M, El Gnaoui S, et al. Prevalence of anxiety disorders: a population-based epidemiological study in metropolitan area of Casablanca, Morocco. Annals of General Psychiatry. 2007;6:6.

13. Chartier MJ, Walker JR, Stein MB. Considering comorbidity in social phobia. Soc Psychiatry Psychiatr Epidemiol. 38(12):728-734

14. Bosc M, Dubini A, Polin V. Development and validation of a social functioning scale, the Social Adaptation Self-evaluation Scale. Eur Neuropsychopharmacol. 1997;7(Suppl 1):S57-S70.

15. Voci SC, Beitchman JH, Brownie EB, et al. The importance of early childhood language impairment. J Anxiety Disord. 20(7):915-930.

16. Schneier FR. Social anxiety disorder. The New England Journal of Medicine. 2006;355:1029-1036.

17. Beesdo K, Bittne Ar, Pine DS, et al. Incidence of Social Anxiety Disorder and the Consistent Risk for Secondary Depression in the First Three Decades of Life. Arch Gen Psychiatry. 2007;64(8):903-912.

18. Stein MB, Fuetsch M, Mu"ller N, et al. Social anxiety disorder and the risk of depression: a prospective community study of adolescents and young adults. Arch Gen Psychiatry. 2001;58(3):251-256.

19. Gaynes BN, Magruder KM, Burns BJ, et al. Does a coexisting anxiety disorder predict persistence of depressive illness in primary care patients with major depression? Gen Hosp Psychiatry. 1999;21(3):158-167.

20. Wittchen H-U, Stein MB, Kessler RC. Social fears and social phobia in a community sample of adolescents and young adults: prevalence, risk factors and comorbidity. Psychol Med. 1999;29(2):309-323.

21. Lecrubier Y, Wittchen H-U, Faravelli C, et al. A European perspective on social anxiety disorder. Eur Psychiatry. 2000;15(1):5-16.

22. Hudson JL, Rapee RM. The origins of social phobia. Behav Modif. 2000;24(1):102-129.

23. Gates L, Lineberger MR, Crockett J, et al. Birth order and its relationship to depression, anxiety, and self-concept test scores in children. $J$ Genet Psychol. 1988;149:29-34. 
24. Kashdan TB, Herbert JD. Social Anxiety Disorder in Childhood and Adolescence: Current Status and Future Directions. Clin Child Fam Psychol Rev. 2001;4(1):37-61.

25. Beidel DC, Turner SM. Shy children, phobic adults: Nature and treatment of social phobia. Washington DC: American Psychological Association. 1998.

26. El-Tantawy AM, Raya YM, Al-Yahya AH, et al. Social phobia among patients attending the outpatient clinics of Buraydah Mental Health Hospital, Al-Gassim, KSA. Current Psychiatry. 2010;17(2):35-43.

27. Hambrick JP, Turk CL, Heimberg RG, et al. The experience of disability and quality of life in social anxiety disorder. Depress Anxiety. 2003;18(1):46-50.
28. Alkhathamia S, Kaviania H, Shorta E. Social anxiety among adolescents and its relation to quality of life. The European Proceedings of Social \& Behavioural Sciences. 2014;218-228.

29. Wittchen HU, Carter RM, Pfister H, et al. Disabilities and quality of life in pure and comorbid generalized anxiety disorder and major depression in a national survey. Int Clin Psychopharmacol. 2000;15(6):319-328.

30. Lochner C, Mogotsi M, Du Toit PL, et al. Quality of life in anxiety disorders: A comparison of obsessive-compulsive disorder, social anxiety disorder, and panic disorder. Psychopathology. 2003;36(5):255-262.

31. Barrera TL, Norton PJ. Quality of life impairment in generalized anxiety disorder, social phobia, and panic disorder. Journal of Anxiety Disorder. 2009;23(8):1086-1090. 